\title{
DOS SERES ALADOS DA ANTIGUIDADE AOS ANJOS DO ROCOCÓ
}

\author{
From Antique Winged Beings to Rococo Angels
}

\author{
Angela Brandão*
}

\begin{abstract}
RESUMO
O presente artigo parte de um objeto pertencente ao Museu Arquidiocesano de Arte Sacra de Mariana: um trono episcopal atribuído a Antônio Francisco Lisboa, entalhado com um esquema decorativo composto por três figuras angelicais, um querubim central e dois anjos de corpo inteiro, despidos. A presença de anjos, Cupidos e crianças entre os elementos que compunham as armações efêmeras para a chegada do primeiro bispo à cidade de Mariana, descritos no relato Aureo Trono Episcopal, de 1749, abriu caminho para uma interpretação ampla e ainda incompleta da transposição das figuras aladas da arte Antiga - especialmente de Eros, por meio do neoplatonismo, para o Renascimento, transposição que será herdada pela arte barroca e rococó.
\end{abstract}

Palavras-chave: anjos; seres alados; arte barroca e rococó.

\begin{abstract}
This article departs from an object belonging to the Archdiocesan Museum of Sacred Art of Mariana: an Episcopal throne attributed to Antonio Francisco Lisboa, carved with a decorative scheme comprises three angelic figures, one cherubim at the middle of two angels full body, naked. The presence of angels, Cupids and children among the elements that made up the ephemeral frames for the arrival of the first bishop of the city of Mariana, described in the report "Golden Episcopal Throne", from 1749, opened the way for a broad and still incomplete interpretation on the transposition of winged figures from Ancient art \footnotetext{
História da Arte na Universidade Federal de São Paulo - UNIFESP. Este artigo resulta de entrecruzamento de diferentes projetos de pesquisa financiados pela FAPEMIG, em 2010; pela FADA, entre 2011-2012, e atualmente relacionados ao Processo n 471680/2013-3 do CNPq (UNIVERSAL-MCTI/CNPq No 14/2013). brandaoangela@hotmail.com
}

Professora do Departamento de História da Arte e do Programa de Pós-Graduação em
\end{abstract}


- especially Eros, through neo-Platonism, in Renaissance, which will be inherited for the Baroque and Rococo art.

Keywords: Angels; winged beings; Baroque and Rococo art.

Para Helena e André

Interessa-me, particularmente, a fronteira que separa as obras de arte dos objetos de uso comum. Talvez, por isso, tenha dedicado alguns dos últimos anos de pesquisa a um cadeirão de jacarandá entalhado, pertencente ao acervo do Museu de Arte Sacra de Mariana, atribuído a Antônio Francisco Lisboa, o Aleijadinho. A talha que coroa o espaldar desse móvel é composta por dois anjos, como meninos desnudos, e um querubim central, portando símbolos do bispado (Figs. 1 e 2). O móvel teria pertencido ao quarto bispo de Mariana, Dom Domingos da Encarnação Pontével, conforme atestado por
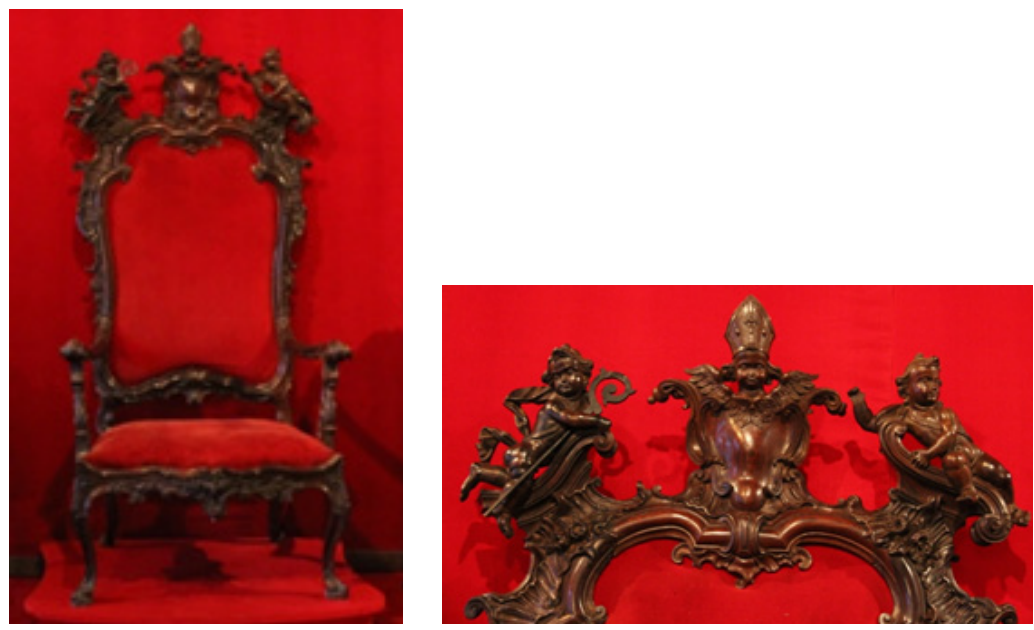

FIGS. 1 E 2 - ANTÔNIO FRANCISCO LISBOA (ATR.). TRONO EPISCOPAL (C. 1778-1783), PERTENCENTE AO BISPO D. DOMINGOS DA ENCARNAÇÃO PONTÉVEL. JACARANDÁ ENTALHADO E ESTOFADO, 210 X 100 X 56 CM. PROVENIENTE DO PAÇO EPISCOPAL DE MARIANA. MUSEU ARQUIDIOCESANO DE ARTE SACRA DE MARIANA, BRASIL. FOTO DA AUTORA. 
seu inventário de morte: "Uma cadeira grande de encosto de talha dourada com seus anjinhos dourados que foi vista, avaliada pelos ditos louvados na quantia de vinte mil-réis"'.

Pontével possuiu uma das maiores bibliotecas do período colonial no Brasil: "Nenhuma dessas bibliotecas, em termos de tamanho, comparava-se à do bispo de Mariana, Dom frei Domingos da Encarnação Pontével, constituída por 412 títulos e 1.066 volumes, quiçá uma das maiores do período colonial"'2. Entre os livros de sua biblioteca estava o relato anônimo, publicado em 1749, que descrevia a chegada do primeiro bispo à cidade de Mariana, após ter sido criada a diocese: o Áureo Trono Episcopal ${ }^{3}$.

Poderia ser uma livre associação de ideias, no entanto, parece sugestiva a presença dos anjos, representados como pequenos meninos desnudos, tanto entalhados no espaldar do trono em jacarandá do Museu de Arte Sacra de Mariana como a constante referência aos anjos, como crianças e Cupidos, nas encenações e armações efêmeras descritas no relato o Áureo Trono Episcopal ${ }^{4}$.

As crianças aparecem, portanto, em alguns momentos do relato das festividades narradas no Áureo Trono, com efeito de jocosidade, alegria e riso, teor escolhido para descrever grande parte do ambiente da festa e tônica dos poemas escritos para a ocasião da chegada do primeiro bispo a Mariana:

Seguia-se as sobreditas figuras uma dança de Carijós, ou gentio da terra. Era esta ajustada de onze mulatinhos de idade juvenil, nus da cintura para cima, a qual cingiam várias plumas caídas até os joelhos, formando saiote: rodeavam as cabeças penachos

1 Inventário de Dom frei Domingos da Encarnação Pontével, 1793, armário I, 4a gaveta, livro. Arquivo Episcopal da Arquidiocese de Mariana.

2 "[...] nela se notava a proeminência das ciências sacras sobre as ciências profanas: logramos identificar 251 obras na primeira seção e 76 na última, respectivamente $60 \%$ e $18 \%$, ficando o restante (85 obras, $21 \%$ ) sem classificação em virtude da falta de dados completos sobre as mesmas. Dentre as ciências sacras, além disso, constatamos igualmente a maior presença de livros de teologia e liturgia [...]." VILLALTA, Luiz Carlos. O diabo na Livraria dos Inconfidentes. In: NOVAES, Adauto. Tempo e História. São Paulo: Secretaria Municipal de Cultura, Companhia das Letras, 1992. p. 372-375.

3 Áureo Trono Episcopal collocado nas Minas do Ouro... Lisboa: Miguel Manescal da Costa, 1749. Edição fac-símile em ÁVILA, Affonso. Resíduos seiscentistas em Minas: textos do século de ouro e as projeções do mundo barroco. Belo Horizonte: Secretaria do Estado da Cultura de Minas Gerais, Arquivo Público Mineiro, 2006.

4 BRANDÃO, Angela. Do relato ao entalhe: o Áureo Trono Episcopal e um cadeirão de jacarandá. Escritos. Revista da Fundação Casa de Rui Barbosa, ano IV, n. 4, 2010. Disponível em: <http:// www.casaruibarbosa.gov.br/arquivos/file/angela.pdf>. 
das mesmas plumas, e outros cingidos de papel pintado, e latas crespas; nos braços, e pernas tinham várias prisões de fitas, maravalhas e guizos; na variedade das mudanças usavam de uns arcos, com que formavam diversos enleios, cantando ao mesmo tempo celebres toadas ao som de tamboril, flautas e pífaros pastoris, tocados por outros Carijós mais adultos, que na grosseria natural dos gestos excitavam motivo de grande jocosidade [sem grifo no original $]^{5}$.

E, especialmente:

Era de meninos o baile, para ser o amor o guia do festejo; pois para se fazer gigante do prazer, nunca passou Cupido da infantil estatura, nem pode deixar o amor de ser sempre menino para se perpetuar o seu gosto. Se já não é por isso que os meninos dançam neste aplauso; porque como S. Excelência Reverendíssima é quem anima este alvoroço público significam os pueris dançadores, que nunca há de envelhecer o gosto, antes será perene a alegria com a assistência de ilustre Príncipe [sem grifo no original $]^{6}$.

Ao lado da referência às crianças, nas festas da chegada do primeiro bispo à cidade de Mariana, surge a refinada associação, um elegante jogo retórico de sobreposições entre o conhecimento religioso e uma artificiosa erudição pagã, bem ao gosto do século XVIII, dos "meninos" e de "Cupido", o pequeno deus Antigo do Amor, filho de Vênus - como se pode ver pela passagem citada.

Partimos, portanto, de um móvel datado de aproximadamente 1790, com a imagem entalhada de três anjos, dois ignudi de corpo inteiro e um querubim, que pertencera ao quarto bispo de Mariana, de um lado; e, de outro lado, de uma narrativa marcada pela descrição de crianças, meninos seminus, anjos e Cupidos, como personagens dos cortejos, das obras de arte efêmeras, dos carros alegóricos e outras armações realizadas para a chegada

5 Áureo Trono Episcopal collocado nas Minas do Ouro... Lisboa: Miguel Manescal da Costa, 1749. Edição fac-símile em ÁVILA, Affonso. Resíduos seiscentistas em Minas: textos do século de ouro e as projeções do mundo barroco. Op. cit., p. 464-465.

6 Ibid., p. 481. 
do primeiro bispo de Mariana, em 1748, cujo livro impresso pertenceu à livraria do quarto bispo de Mariana.

Boa parte dos esforços de pesquisa sobre tais imagens levou-me a tentar compreender as matrizes visuais destes elementos simbólico-decorativos: os querubins e os anjos portadores de mensagens. O que nos remeteu, certamente, ao referencial do barroco italiano e sua transposição para a escultura luso-brasileira. O caminho, já apontado por Germain Bazin, conduzia-nos da escultura de Bernini para a cátedra de São Pedro, no Vaticano, aos anjos e querubins monumentais como elementos da arquitetura de Borromini - portanto, ao cerne do problema das origens da visualidade barroca. Este caminho passava pelo deslocamento da linguagem e de repertório escultórico do barroco romano do século XVII para o universo das esculturas para Mafra, em Portugal do século XVIII e, daí, em direção à arte no Brasil do Setecentos?

Uma das fontes gráficas possíveis para a transposição dos modelos representativos europeus e, neste caso, especialmente italiano, para a utilização de anjos na arte colonial brasileira teriam sido, segundo Marcos Hill $^{8}$, as edições ilustradas da Iconologia de Cesare Ripa (Fig. 3) que circularam provavelmente no mundo luso-brasileiro. É possível supor que, entre as fontes gráficas para a transposição dos modelos de anjos italianos e de suas derivações na arte portuguesa, como as gravuras, as Bíblias e Missais ilustrados, os artífices brasileiros poderiam ter-se inspirado nas ilustrações do livro de emblemas de grande circulação entre os séculos XVI e XVIII. Justamente, o modelo de um fanciulo alado, uma representação de Eros menino para a iconografia do "Amor Domado" nas páginas da Iconologia de Cesare Ripa, poderia ter sido, conforme Hill, modelo direto ou indireto para um dos anjos do lavabo em pedra-sabão da Sacristia da Igreja de São Francisco de Assis de Ouro Preto (Fig. 4).

De fato, a abundância e a onipresença de anjos na arte barroca e no rococó no contexto luso-brasileiro, assim como em suas matrizes italianas, levaram a que se considerasse o "saber fazer", entalhar e esculpir tais figuras, como um dos critérios de aprovação dos artífices que pretendiam

7 BAZIN, G. O Aleijadinho e a escultura barroca no Brasil. Rio de Janeiro: Record, 1963. p. $186-189$.

8 HILL, Marcos. Conferência apresentada durante o VI Congresso do CEIB - Centro de Estudos da Imaginária Brasileira, Casa de Rui Barbosa, Rio de Janeiro, 2010. 


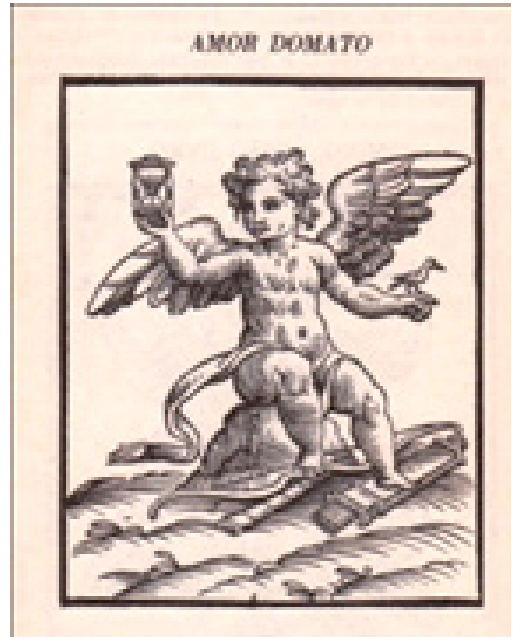

FIG. 3 - GIUSEPPE CESARI, DETTO IL CAVALIER D'ARPINO. AMOR DOMADO. (ILUSTRAÇÕES PARA ICONOLOGIA DE CESARE RIPA) ROMA, 1603.

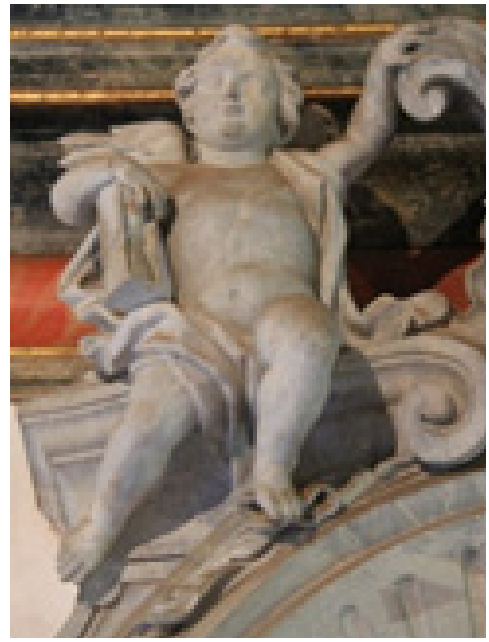

FIG. 4 - ANTÔNIO FRANCISCO LISBOA. ANJO COM AMPULHETA. DETALHE DO LAVABO DA SACRISTIA DA CAPELA DA ORDEM TERCEIRA DE SÃO FRANCISCO DE ASSIS, 1774-1775 C. OURO PRETO. (FOTO DA AUTORA)

examinar-se como entalhadores. Conforme o Livro dos Regimentos dos Oficiais Mecânicos (conjunto de leis que definiu as atividades artesanais em Portugal e suas Colônias, do século XVI ao XVIII), para o exame de entalhador o artesão teria que realizar um friso com ornamentos romanos, muito bem ordenados e, no centro, teria que esculpir: "um serafim muito bem feito e de formoso rosto e em tudo segundo a ordem e o desenho que aqui vai $[\ldots]^{9}$ '. Supõe-se que o Livro dos Regimentos, em várias passagens, remetesse o artesão que se submetia ao exame a um desenho que lhe serviria de modelo. Nada sabemos a respeito desses modelos, uma vez que, ao observar o manuscrito original no Arquivo da Câmara Municipal de Lisboa, não encontramos nenhuma ilustração sequer, com exceção da portada.

9 Livro dos Regimentos dos officiaes mecanicos da mui nobre e sëpre leal cidade de Lixboa -1572. Publicado e prefaciado pelo Dr. Vergílio Correia. Coimbra: Imprensa da Universidade, 1926. p. 111. 
No entanto, não se tratava apenas disso. Ainda que não fosse de pouca monta compreender as transposições de modelos dos anjos barrocos e rococós da arte italiana para Portugal e Brasil, pretendia dar um passo atrás no tempo. Ir mais longe, em direção à imagem dos anjos no tempo, significava enfrentar uma abordagem cronologicamente assustadora e reconhecer, ainda mais, limitações e incompetências.

Em outras palavras, como aventurar-me em direção à Antiguidade Greco-Romana e buscar compreender as raízes visuais da representação dos anjos cristãos nos seres alados do mundo pagão ${ }^{10}$ ? Por que num relato do século XVIII, elaborado a partir de uma festa sacra em torno das celebrações para a chegada de um primeiro bispo, um tema pagão tão contundente quanto Eros menino poderia aparecer de modo tão explícito? Por que num móvel de honra, dedicado a um bispo de Mariana, os anjos portadores de símbolos episcopais obedeciam a uma iconografia inspirada nas representações antigas do Eros menino - como, de resto, em grande parte das representações de anjos desde o Renascimento? Como se teria dado, visual e textualmente, a passagem do modelo de representação dos seres alados da Antiguidade pagã para os anjos cristãos? Não poderia responder a nenhuma dessas perguntas, se não apenas de modo insuficiente e provisório.

Uma das maneiras de arranhar o problema era compreender, ainda que de modo superficial, as representações de personagens alados na arte Greco-Romana, especialmente aqueles que pareciam ter inspirado mais diretamente os modelos de representações dos anjos cristãos, a partir do Renascimento. Durante toda a Idade Média, como se sabe, os anjos foram predominantemente representados como seres jovens, alados, porém de corpos delgados, sexualidade atenuada e completamente vestidos, muitas vezes quase incorpóreos. Em raríssimos casos, os anjos apareciam como crianças. Exemplos desta exceção são alguns dos anjos que participam da cena de pranto sobre o Cristo morto de Giotto di Bodone - um artista particularmente atento a remanescentes pinturas e esculturas romanas - na Capela Scrovegni em Pádua, Itália (Fig. 5).

10 Nos limites de uma nota não seria possível cumprir, minimamente, com as referências à bibliografia sobre o tema da sobrevivência do paganismo na cultura moderna Ocidental, que, por si só, ocupa bibliotecas inteiras. 


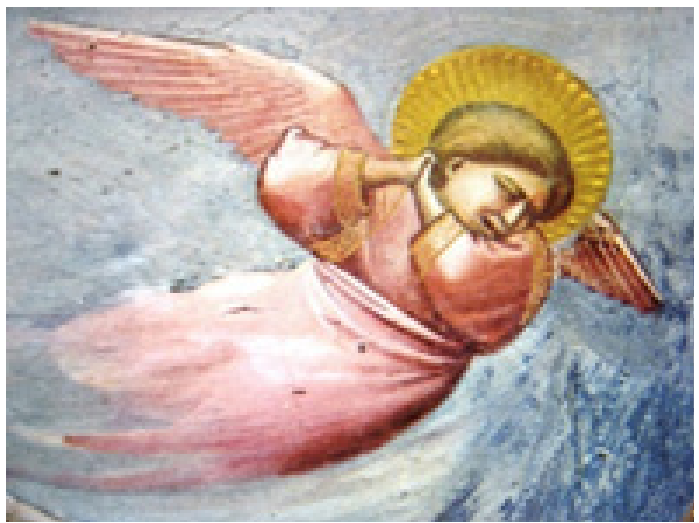

FIG. 5 - GIOTTO DI BODONE. LAMENTO SOBRE O CRISTO MORTO, 1300-1305. DETALHE. AFRESCO. CAPELA SCROVEGNI, PÁDUA, ITÁLIA.

Poderíamos afirmar, no entanto, que, embora houvesse anjos como pequenos meninos vestidos, os anjos como bebês despidos e dotados de exuberância corpórea inexistiram na arte medieval até que o Renascimento italiano realizasse uma curiosa operação visual: a aplicação do modelo do Eros menino para a representação dos seres angelicais. Caberia serem lembrados exemplos em que a representação de Eros menino na pintura renascimental foi aplicada com seu sentido original e pagão, como talvez nas pinturas em afresco da Camera degli Sposi, no Palácio em Mantua, de Andrea Mantegna (Figs. 6 e 7), ou no Cupido da Primavera, de Sandro Botticelli, da Galeria degli Uffizzi. No entanto, o mesmo contexto artístico que fizera renascer elementos da antiguidade clássica, como Eros, fez também o processo de cristianização dos mitos - neste caso, uma "angelização" de Eros.

Entre os seres alados da Antiguidade pagã, concentrei-me em reconhecer minimamente Nice, Niké ou Vitória, os Ventos, Ícaro e Eros. Talvez, os anjos representados como jovens de sexualidade atenuada, nus ou seminus, tivessem suas matrizes visuais não apenas no Eros em sua forma juvenil, mas também a entidade feminina da Vitória para os Antigos. 


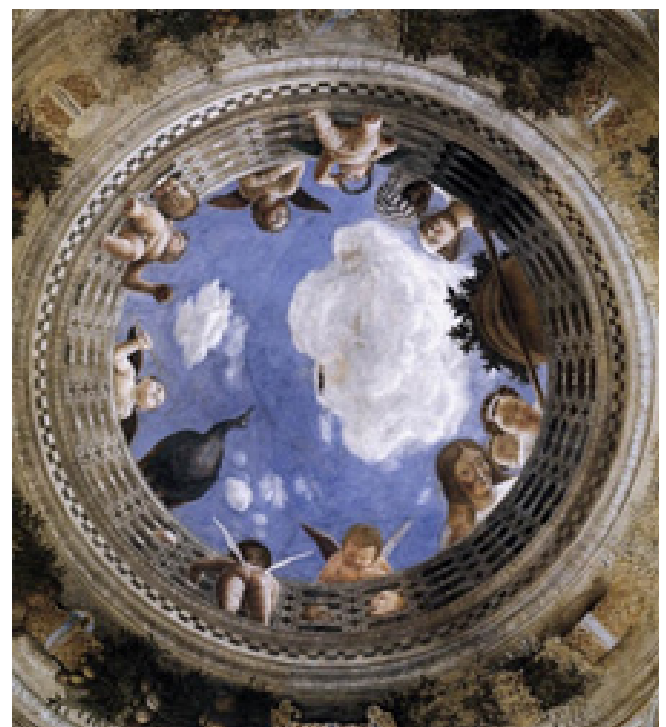

FIG. 6 - ANDREA MANTEGA. ÓSCULO DA CAMARA DEGLI SPOSI, 1465-1474. AFRESCO. CASTELLO DI SAN GIORGIO. MANTUA.

FONTE: http://upload.wikimedia.org/wikipedia/commons/8/82/Camera_picta,_ceiling_3.jpg

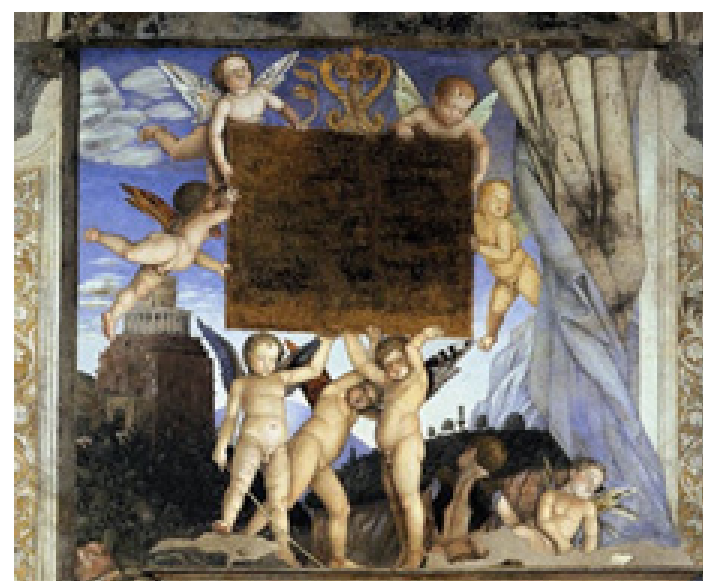

FIG. 7 -ANDREA MANTEGNA. CAMERA DEGLI SPOSI. AFRESCO 300X800CM, DETALHE. CASTELLO DI SAN GIORGIO. MANTUA. 1465-1474.

FONTE: http://upload.wikimedia.org/wikipedia/commons/8/82/Camera_picta,_ceiling_3.jpg 
A condição assexuada das figuras angelicais teria permitido a apropriação da figura feminina de Nice, personificação da Vitória, pertencente à primeira Estirpe divina, filha do Titã Palante e de Estige. Niké muitas vezes equivalia à Atenas Alada e foi representada, tradicionalmente, como uma mulher com grandes asas alçadas com coroa de louro e ramos de palma na mão ${ }^{11}$. Pode-se supor que as Nikés ou Vitórias, para os romanos, tenham sido tomadas como modelo para algumas representações de anjos jovens e adultos, especialmente os arcanjos, embora num sistema de sobreposições de feminino e masculino.

Também alados eram, em suas representações, os Ventos, filhos de Eos ou Aurora e Astreo. Dividiam-se em quatro ou oito entidades: Bóreas, o vento do Norte (ou Aquilão), que representava a rudeza. Ao enamorar-se da Ninfa Orítia, sem obter êxito, raptou-a e gerou dois filhos alados que acompanhariam os Argonautas. Zéfiro, o vento Oeste (ou Favônio), que representa a delicadeza, o amante de Flora imortalizado por Sandro Botticelli em "O Nascimento de Vênus", de 1483. Também havia os ventos Nótos ou Áuster, o vento Sul; e Eurus ou Euro, o vento Leste; e ainda os ventos Kaikias, Lips, Apeliotes e Siroco ${ }^{12}$. Os Ventos aparecem representados nos relevos em pedra da Torre dos Ventos, em Atenas, um edifício octogonal do século I a.C., na Ágora Romana (Fig. 8). As representações dos Ventos poderiam ter sido utilizadas como modelo, assim como as Vitórias, para imagens de anjos de corpo jovem e adulto. Seu pertencimento ao mundo aéreo carregava uma possibilidade de adaptação iconográfica e iconológica por si mesmo, como veremos adiante ao ler a Hierarquia Celestial do Pseudo Dionísio, o Areopagita.

Detive-me, brevemente, em torno do personagem alado artificialmente, Ícaro, filho de Dédalo, o maior dos arquitetos. A história é bastante conhecida. Dédalo criou, como se sabe, asas de cera para si e para o filho a fim de fugirem do Labirinto. Dédalo conseguiu voar até a costa da Sicília, mas Ícaro se entusiasmou ao voar e subiu alto demais até que o sol derretesse suas asas. Caiu ao mar e morreu ${ }^{13}$. A iconografia de Ícaro, menos abundante na Antiguidade e em seu reviver no Renascimento, se comparada à de Eros

11 DOSSI, Eugenia et al. Antichità Classica. Repertorio generale della civiltà greco-romana. Torino: Garzanti, 2000. p. 962-963,1509. Permito-me, provisoriamente, parafrasear, nas linhas que se seguem, alguns dos verbetes do Dicionário Garzanti sobre Antiguidade Clássica.

12 Ibid., p. 1492

13 Ibid., p. 695. 


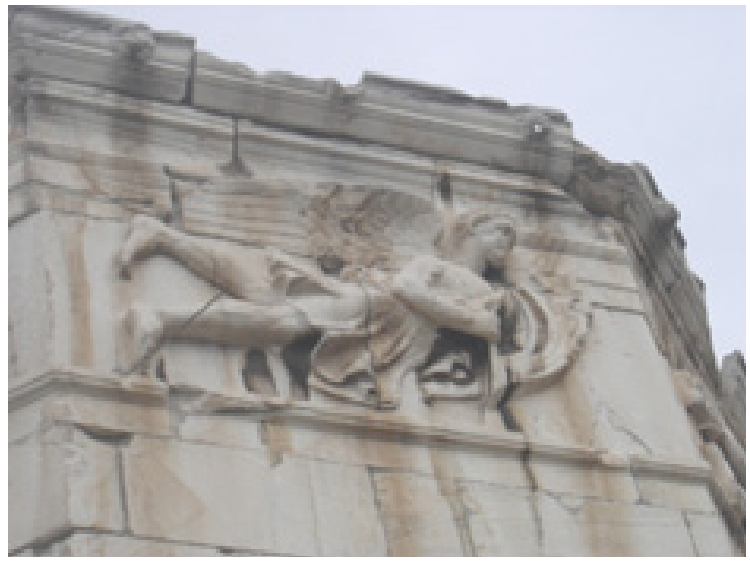

FIG. 8 - VENTO. TORRE DOS VENTOS. APROX. 50 A.C. RELEVO EM MÁRMORE. ÁGORA ROMANA, ATENAS. FOTO DA AUTORA.

e à de outros seres alados, reapareceu no Neoclassicismo. Poderia ser analisada a utilização de Ícaro como modelo para a representação de arcanjos, anjos jovens e adultos, assim como os modelos de Vitória e dos Ventos.

Não obstante, entre todos os seres alados da Antiguidade, não resta dúvida de que o principal deles a fornecer o modelo de representação de anjos a partir do Renascimento foi Eros, sobretudo em sua forma infantil. Eros foi compreendido, para a cultura grega, como entidade cósmica primordial, o princípio animador do universo, por meio do qual tudo foi criado. Uma força capaz de atrair fisicamente e sexualmente os seres humanos, responsável pela manutenção da espécie e pela coesão do Cosmos. Homero o evoca como violento desejo físico que faz tremer os membros. Nos poetas líricos dos séculos VII e VI a.C. a potência de eros é refinada e descrita como audaz, intratável, capaz de brincar com os desejos humanos. Na poetisa Saffo, eros era ainda um vento que sopra sobre os carvalhos, mas também memória, dá alegria e sofrimento, é doce e amargo ${ }^{14}$.

O eros platônico, exposto por Diotima no Banquete, baseava-se no mito platônico do nascimento de Eros, filho da Pobreza e do Expediente, 
tinha um significado filosófico-religioso. Eros não era dotado de beleza e sabedoria, mas desejava possuí-las. Para Platão (428-347 a.C.), eros seria uma força destinada a culminar numa dupla carência: a distância dos homens em relação à ideia eterna e a separação do andrógino primordial em criaturas do sexo masculino e feminino. Portanto, Platão considerava a contemplação da beleza ideal, solicitada por eros, superior à adesão da alma à sedução sensual da beleza fenomênica ${ }^{15}$. O pensamento platônico deixou um traço profundo no desenvolvimento da doutrina do amor cristão, o ágape. O eros de Platão tendeu a combinar-se com a doutrina de Santo Agostinho (354430) acerca do Espírito Santo como amor, como uma escala de perfeição que conduz à contemplação da divindade ${ }^{16}$.

Além da importância em se compreender, minimamente, o significado de eros (com letra minúscula), ou seja, como energia ou potência, tratava-se de compreender Eros em sua concepção como divindade e sua representação visual (com "e" maiúscula). Nas Teogonias mais antigas, Eros era um deus primordial, nascido ao mesmo tempo em que a Terra se formara e criado na origem do Cosmos, um deus primordial que nasce do Caos. Surgido do Ovo primordial, gerado pela Noite, cujas metades se dividiram formando a Terra e o Céu, Eros será sempre, mesmo com a estetização de sua lenda, divinizado como força primordial do Mundo, capaz de assegurar a continuidade da espécie e a coesão interna do Cosmo. Considerado como filho de Ilítia e Íris ou de Hermes e Ártemis Ctônia, ou mais comumente foi aceita a tradição de que Eros seja filho de Hermes e Afrodite, para os gregos, e de Vênus e Marte para os romanos. A representação de Eros por símbolos anicônicos ou fálicos, com os quais foi venerado em seus principais santuários, em Atenas e na Beócia, foi progressivamente substituída por uma iconografia que o apresentará, originalmente, como ser alado jovem e adulto, com ênfase em seu falo e, sucessivamente, como um menino, frequentemente alado, que se diverte em perturbar os corações, inflamando-os com sua tocha ou ferindo-os com sua flecha ${ }^{17}$.

Portanto, o jovem Eros passou a ser "substituído" por sua representação como um menino alado, com atributos como a tocha nas mãos para queimar e o arco e flecha para ferir. Entre as inúmeras representações

15 PLATONE. Simposio, in Platone, Tutti gli Scritti. Milano: Bompiani. 2000. p. 511-518.

16 DOSSI, Eugenia et al. Op. cit., p. 517.

17 Ibid., p. 517-518. 
e significados de Eros na arte da Antiguidade, estavam o jovem despido e alado; a criança despida, alada, com arco e flecha; a criança despida, alada e vendada; a criança despida, alada, com tocha; a criança despida e adormecida - esta muito comum em sarcófagos. Em casos mais raros, a representação de Eros se fez de modo episódico: a criança que joga com nozes (bile) com meninos divinos (Ganimede ou Anteros) ou o menino castigado pela mãe por colher rosas e ferir-se com os espinhos. Na religiosidade clássica, Eros foi parcialmente marginalizado, mas ocuparia o primeiro plano na religiosidade helenística de fundo dionisíaco e mistérico, recuperando sua antiquíssima tonalidade noturna e de uma força que agia de modo soberano no reino da vida e da morte. As inúmeras figurações helenísticas e romanas dos eroti ou amorini foram frequentemente tomadas como símbolos dos neófitos, durante a iniciação, ou da passagem da alma ao Além, aquele que acompanhava as almas ao Além -, daí sua constante presença nos sarcófagos romanos. Assim também se fez representar de modo multiforme, como Erotes ou Amorini (os Cupidos, para os romanos), em pinturas, mosaicos ou grupos escultóricos, ao lado de Vênus ou de Psiquê ${ }^{18}$.

Mas, como se teria dado, afinal, a passagem renovada da representação dos seres alados da Antiguidade, e especialmente de Eros, como anjos, ao Renascimento e, por derivação, sua adoção sistemática pela arte barroca e rococó? Deverão haver muitas e outras respostas. Um desvio na investigação me permitiu adiar, em parte, o entendimento dos anjos nas tradições judaica e muçulmana, uma vez que, afinal, os anjos constituem seres presentes nas três grandes religiões monoteístas fundamentadas em seus respectivos livros sagrados ${ }^{19}$. A leitura do Velho Testamento, no entanto, indicaria o caminho para compreender as manifestações dos anjos como narradas no texto bíblico e fundamentais para o cristianismo. Fui em busca, porém, de pelo menos uma possibilidade de averiguação: a leitura de Dionísio Areopagita por Marsilio Ficino.

18 Idem.

19 Ver AGAMBEN, Giorgio; COCCIA, Emanuele. Angeli. Ebraismo, Cristianesimo, Islam. Neri Pozza, 2014, e BUSSAGLI, Marco. Storia degli Angeli. Milano: Rusconi, 1995. 
Pseudo Dionísio, o Areopagita, foi provavelmente um autor do início do século VI d.C., tratadista e filósofo neoplatônico grego, convertido ao cristianismo. Tentou conciliar diversas tradições culturais e filosóficas com o cristianismo e se faz passar por Dionísio (personagem do século I d.C.), este convertido pelo apóstolo Paulo no Areópago ateniense, que se tornou o primeiro Bispo de Atenas ${ }^{20}$. O pensamento do autor que se fez passar por Dionísio Areopagita propunha a existência do "Uno" (Deus). Seus escritos definiram um método para alcançar a compreensão mais alta e perfeita de Deus por meio do reconhecimento daquilo que Ele não é: a chamada Teologia negativa ou apofática versus uma Teologia positiva ou catafática. Conhecer a Deus dizendo o que Ele não é, segundo o pseudo Dionísio, levaria à consciência de que Ele não é nada, nenhuma coisa finita. Tal atitude meditativa conduziria ao "silêncio místico", como uma douta experiência religiosa.

Tratava-se de observar, especialmente, um dos textos que fazem parte do corpus documental associado ao pseudo Dionísio, o Areopagita, por ser o mais completo texto a guiar durante toda a Idade Média e para além dela a compreensão que se teve acerca dos anjos. Em sua Hierarquia Celestial, o autor do século VI estabeleceu os seguintes níveis celestiais: Primeira Tríade (composta por Serafins, Querubins e Tronos). Estes seres estariam mais diretamente ligados a Deus. Serafins, em hebraico "aqueles que ardem"; querubins: a "plenitude e efusão da sabedoria". A Segunda Tríade (formada pelas Dominações, Potências e Potestades) e a Terceira Tríade (Principados, Arcanjos e Anjos). Apenas os Anjos poderiam entrar em contato com os seres humanos. "Deus fala e os anjos transmitem Sua mensagem $[\ldots]^{21}$ ".

As manifestações dos anjos no Antigo Testamento, as Sagradas Escrituras, como o autor se refere a elas, fundamentaram a "helenização do cristianismo ${ }^{22}$ " proposta por pseudo Dionísio, por meio de uma tentativa de tornar visíveis estes seres que se manifestam, no texto bíblico, de modo não humanizado, não corpóreo, mas apenas como vozes, luzes ou chamas, por exemplo. Nas palavras do autor: "Pois que não é de fato possível que nossa

20 REALE, Giovanni. Introduzione. Il Corpus Dionysiacum e i Grandi Problemi che suscita per la sua Interpretazione. In: Dionigi Areopagita, Tutte le Opere. Milano: Bompiano, 2009. p. 11-29.

21 DIONIGI AREOPAGITA. Gerarchia Cleleste in Tutte le Opere. Op. cit., p. 105, 111.

22 BEIERWALTER, p. 55 apud REALE, G. Op. cit., p. 17. 
mente nos eleve em direção àquela imaterial imitação e contemplação das hierarquias celestes sem o uso de um guia material, se pensa que as belezas visíveis são imagens das belezas invisíveis $[\ldots]^{23}$ ". Ao mencionar a beleza visível e a necessidade de um "guia material", Dionísio indicaria, quiçá, um princípio de representação visual para os seres angelicais.

De fato, nem alcançaríamos, talvez, da dúvida à busca e, mediante a exata indagação das coisas sacras, à elevação espiritual, se não nos tivesse perturbado a deformidade das figurações explicativas dos anjos, as quais não permitem que nossa inteligência se detenha aos símbolos inconvenientes, mas a incita a renegar as afeições materiais e a habitua a santamente subir, através das coisas visíveis, às alturas sobremundanas ${ }^{24}$.

Assim escreveu o autor do século VI sobre a imagem e representação dos anjos:

Mas representam (as Sagradas Escrituras) os anjos também sob o aspecto humano, para que o homem possa compreender, fixada em direção ao alto, a sua potência visível [...] A adolescência e a juventude dizem o constante florescimento de sua potência vital $[\ldots]^{25}$.

Poder-se-ia extrair, da Hierarquia Celestial de Dionísio, a forma humana para os seres angelicais e sua jovialidade. Parece, portanto, justificar-se teologicamente que os anjos jamais serão representados como adultos ou anciãos, se não sempre jovens ou meninos.

Pseudo Dionísio apresentou definitivamente o caráter alado dos anjos e sua capacidade de voar também com uma justificativa teológica, mas também como uma indicação visual:

Por isto a Escritura pôs asas nos pés das santas inteligências; de fato, a asa significa a potência de subir ao alto e o gosto pelo 
céu, o meio de subir ao alto e de fugir através da altura de tudo o que é baixo; a leveza das asas significa que não tem nada de terrestre, mas se elevam de modo perfeitamente puro e privado de peso em direção ao alto $^{26}$.

Esse caráter aéreo dos anjos seria confirmado não apenas por sua natureza alada, mas por sua associação com os ventos e as nuvens.

O fato de se atribuir a eles o nome dos ventos indica a sua ação veloz e que passa em todas as coisas quase intemporalmente e o movimento que transporta do alto ao baixo e de novo do baixo ao alto, que direciona os seres inferiores em direção a uma altura superior e que conduz os superiores em direção a um processo comunicativo e providencial no que concerne aos inferiores $[\ldots]^{27}$.

E ainda: "Mas a Sagrada Escritura lhes representa também sob a forma de nuvens, indicando com isto que as sagradas inteligências são preenchidas de modo sobremundano de uma luz escondida e acolhem simplesmente a primeira luz em sua primeira emanação $[\ldots]^{28 \%}$.

Um indício teológico para compreender e justificar a nudez dos anjos, que será de fato revelada visualmente pela arte apenas no Renascimento, poderíamos localizar no seguinte trecho:

Os pés nus e o ser privado de calçados indica que são livres, soltos, expeditos e puros de acréscimo de coisas externas e que, tanto quanto é possível, informam a simplicidade divina ${ }^{29}$.

Se a nudez dos anjos poderá ser compreendida como liberdade, simplicidade, soltura e desvencilhamento das coisas externas, as vestes sacerdotais indicariam sua capacidade de elevação do humano ao divino. Mas, "a veste sacerdotal significa sua capacidade de conduzir em direção 
a visões divinas e místicas e a consagração de toda a vida dos homens ${ }^{30 "}$. Portanto, os anjos poderiam ser representados nus, mas não necessariamente. Ao lado da juventude ou infância que caracterizaria a imagem possível dos anjos, Dionísio nos explica, também, a alegria que lhes é inerente:

Faltaria ainda explicar o discurso relativo à alegria das disposições celestes. Eles, de fato, em nenhum modo são passíveis do prazer que constitui para nós a alegria, mas se diz que gozam junto com Deus pelo reencontro dos perdidos, segundo um prazer tranquilo próprio de Deus e segundo a alegria inexprimível a qual frequentemente também os homens santos têm participado em graça das visitas deificantes das iluminações divinas ${ }^{31}$.

Não havia, no texto bíblico, uma descrição exata e constante da aparência dos anjos e sua forma física, com base na tradição hebraica. $\mathrm{O}$ texto Hierarquia Celestial estabelecia, possivelmente, ou reunia elementos descritivos dessas figuras incorpóreas para que os artistas passassem a guiar-se ou ser guiados no momento de representá-los, de dar-lhes corpo e forma. A partir de Pseudo Dionísio, o Areopagita, e de sua releitura no Humanismo, era possível encontrar elementos teológicos e visuais que justificassem a representação das disposições celestiais como seres jovens, alados, nus e alegres - o caminho para a utilização dos Eros Meninos estaria, em parte, traçado.

O chamado Corpus Dionysiacum foi conhecido e lido por estudiosos e autores da Idade Média, como Tomás de Aquino (1225-1274) ${ }^{32}$. Porém, a descoberta da "falsidade" dos textos de Dionísio Areopagita seria discutida apenas no final do período medieval. Para Giovanni Reale, somente a partir do Renascimento se aceitou definitivamente que os escritos do Corpus eram posteriores ao que o autor tentara fazer crer a seus leitores ${ }^{33}$. No entanto,

30 Idem.

31 Idem.

32 REALE, Giovanni. Op. cit., p. 15, 23 e BELLINI, Enzo. Saggio Introduttivo. In: DIONIGI L'AREOPAGITA (Pseudo). Op. cit., p. 37, 43.

33 Ibid., p. 23. 
a revelação de que o Corpus Dionysiacum se tratava de escritos "falsos" não obscureceu sua importância durante o Renascimento. Ao contrário, um renovado interesse pelos escritos de Dionísio acentuou-se no círculo do Humanismo e do tardo Neoplatonismo na Florença de segunda metade do século XV. Um dos mais importantes representantes desse ambiente, Marsilio Ficino (1433-1499) ${ }^{34}$, ligado ao círculo de eruditos em torno da família dos Médicis, escrevera a respeito de Dionísio: "Platonicus primo ac deinde Christianus ${ }^{35}$ ".

Enzo Bellini, citando os estudos de Allo Stiglmayr sobre Dionísio, escreveu que "entre Dionísio e o tardo Neoplatonismo há semelhança de termos, de fórmulas e de doutrinas, como aquelas sobre o Belo e sobre Eros, enquanto que com a religião mistérica há uma certa semelhança no uso da linguagem simbólica e no modo de conceber a união estática com o Divino". E ainda: "Cada um dos nomes [divinos] examinados vem justificado com referência às Sagradas Escrituras [...] mas de fato coincidem com os nomes usados nas escolas neoplatônicas para indicar o Divino. Tal é o primeiro nome 'perfeito e manifestador de todas as procissões divinas' o 'Bem' (com os equivalentes, Belo, Beleza e Eros) ${ }^{36}$ ". Com isso, queremos concordar que já havia uma cristianização de Eros no Neoplatonismo do pseudo Dionísio. Pela semelhança com os passos e símbolos que seriam usados pelo tardo Neoplatonismo, no ambiente florentino do primeiro Renascimento, Eros será novamente invocado, como se pode ver pelos escritos de Marsílio Ficino. Interessa-nos particularmente o texto Sopra lo Amore ovvero Convito di Platone $^{37}$ [Sobre o Amor ou o Banquete de Platão]. A referência direta, desde o título, ao Banquete de Platão sugere o diálogo neoplatônico em torno do tema do amor. Porém, o texto de Ficino remetia não somente ao Simpósio de Platão, mas também aos escritos de Dionísio, o Areopagita. Cito:

AAlma do Mundo, isto é, a da primeira matéria, e as Almas das doze esferas, e das Estrelas, porque seguem Deus supremamente, e os Anjos Divinos são chamados pelos Platônicos Deuses

34 HALE, John R. (Org.). Dicionário do Renascimento Italiano. Rio de Janeiro: Jorge Zahar, 1981. p. 144-145.

35 Marsilii Ficini Opera. Basilea, 1561 reedição anastática. Torino, 1959, I, p. 768 apud REALE, Giovanni. Op. cit., p. 18. Trad. livre: "Platônico, em primeiro lugar Cristão".

36 BELLINI, Enzo. Op. cit., p. 56.

37 FICINO, Marsilio. Sopra lo Amore ovvero Convito di Platone. Milano, Se: 1998. 
mundanos. [...] E aqueles [Deuses] bons, que têm custódia de nós, são pelo próprio nome chamados Anjos por Dionísio Areopagita, governantes do mundo inferior: sobre isso não discorda da Mente de Platão. Podemos ainda, segundo o uso de Dionísio, chamar Anjos Ministros de Deus aqueles espíritos que Platão chama os Deuses e almas das esferas e das Estrelas. O que não é discordante de Platão [...]. De modo que entre Platão e Dionísio há diferença de palavras mais do que de sentenças ${ }^{38}$.

A aproximação entre Platão e Dionísio Areopagita, proporcionada por Marsílio Ficino, talvez tenha permitido uma das formas de combinação entre Eros Menino e os Anjos. Em outras palavras, a divinização de eros pelo pensamento de Platão, no Banquete, e celebrada por meio do tardo Neoplatonismo de Ficino, em seu Sopra lo Amore, de um lado, e, de outro lado, a divinização dos anjos pelos escritos de Dionísio Areopagita, tal como interpretados por Ficino, providenciaram, possivelmente, algumas das bases filosófico-religiosas para a operação iconográfica de representar os anjos como Eros menino. Tratava-se de uma interpretação cristã do platonismo ou de uma interpretação platônica do Cristianismo, assim como de uma integração do pensamento pagão com os dados do Cristianismo, o "sumo daquele sincretismo pagano-cristão, que foi a tentativa original dos humanistas, do qual Marsílio foi o principal fator ${ }^{39}$ ".

Esta operação ocorre, justamente, no mesmo contexto cultural em que se desperta o interesse anatômico e individualizante em relação ao corpo infantil. A imagem da criança, até então compreendida como um adulto em miniatura, passou a receber um tratamento específico, desde a Antiguidade, somente na Primeira Idade Moderna ${ }^{40}$.

Segundo Philippe Ariès, a imagem da criança nua, o putto, era desconhecida na Idade Média. Os putti surgiram no século XVI, representando a revivescência do Eros helenístico, invadiram a pintura e se tornaram um motivo decorativo repetido ad nauseam. O século XVII não pareceu cansado do tema e a pintura religiosa adotou-os à exaustão

38 Ibid., p. 92-93.

39 RENSI, Giuseppe. Postfazione. In: FICINO, Marsilio. Sopra lo Amore: ovvero Convito di Platone. Op. cit., p.164-165.

40 Ver ARIÈS, Philippe. História social da criança e da família. Rio de Janeiro: Guanabara, 1981. p. 61-63. 
graças à transformação do anjo-adolescente medieval em putto. Com exceção do anjo da guarda, de agora em diante o anjo não seria mais o adolescente que ainda se vê nas telas de Botticelli: ele se transformara num pequeno Eros nu, mesmo quando também para satisfazer o pudor pós-tridentino, sua nudez era encoberta por nuvens, vapores ou véus. A nudez do putto conquistou até mesmo o menino Jesus e as outras crianças sagradas. [...] O gosto pelo putto correspondia a algo mais profundo do que o gosto pela nudez clássica, a algo que deve ser relacionado com um amplo movimento de interesse em favor da infância ${ }^{41}$.

Os anjos, antes figuras incorpóreas ou solenes, passaram a receber definitivamente um tratamento visual como bebês de corpos exuberantes e rechonchudos, como Eros menino pagão, dados à graciosidade e às travessuras infantis.

A arte Barroca e Rococó, dos séculos XVII e XVIII, tornou-se herdeira dessa operação realizada pelo pensamento e pela arte renascimental, sem precisar justificar mais, nem do ponto de vista teológico nem do ponto de vista artístico, a utilização do modelo dos meninos alados, inspirados no Eros pagão, para a representação dos anjos. O século XVII veria compor-se uma ampliação do emprego das figuras angelicais, em suas diferentes formas - anjos, querubins, serafins - em diversas manifestações artísticas - pintura, escultura, arquitetura, mas também nas gravuras e nas artes aplicadas. As figuras angelicais teriam sua presença multiplicada em explosões celestiais, tendo seu sentido de humor e graça acentuado, assim como suas irreverentes posturas travessas, carregando atributos, símbolos, sinais, tarjas, emblemas e escudos; dialogando e circundando as imagens dos santos e as cenas bíblicas.

A carga teológico-filosófica que alimentara a transposição de Eros Antigo ao anjo cristão nos séculos XV e XVI foi sendo assimilada e "naturalizada" por artistas e artesãos a ponto de esvaziar-se num certo convencionalismo. Giuseppe Rensi, ao posfaciar o escrito Sopra l'Amore,

$41 \quad$ Ibid. p. 62. 
de Ficino, considerou mesmo que já no século XVI os tratados sobre o amor teriam perdido seu frescor:

A especulação filosófico-mística em torno do amor, que tanto ocupou os nossos escritores antes e durante o Renascimento, e forma grande parte do conteúdo da sua prosa e poesia, tem justamente neste pequeno volume [Sopra lo Amore] sua expressão mais plena, completa e madura. [...] E se republicam-se hoje e se leem os tratados de amor do cinquecento, que representam a decadência e a degeneração desta especulação sobre o amor, tanto mais era oportuno trazer novamente à luz um tratatello, como este, fruto do momento e do homem, nos quais tal especulação não tinha ainda se tornado artifício, convenção ou zombaria, mas conservava uma fé intelectual viva, animada do entusiasmo devoto com o qual a cultura superior e mais refinada da época, precisamente e sobretudo em Marsílio, como seu mais perfeito expoente, tinha descoberto, abraçado, revivido em si o antigo pensamento platônico-alexandrino ${ }^{42}$."

Pois, nos séculos XVII e XVIII, o que seria retido na representação dos anjos como Eros menino não era já "uma fé intelectual viva ou um reviver em si do antigo pensamento platônico-alexandrino", mas justamente o artifício, a convenção e a jocosidade. O século XVIII, compreendido como herdeiro da arte barroca, porém em seu desdobramento específico no rococó, muitas vezes reconhecido como um período de esvaziamento do peso simbólico e religioso da imagem em direção ao profano, ao mundano e ao festivo, abrigou uma legião de anjinhos açucarados e entendidos como "mera decoração".

No século XVII, o fausto ainda podia ser manifestação simbólica de um carisma da realeza ou da nobreza; no século XVIII, pelo contrário, o objeto de luxo representa apenas a riqueza transformada em objeto, tornada tangível; a sua beleza não remete para nenhum antecedente espiritual; deixou de exprimir, refletindo-a, uma autoridade que brilha no mundo das aparências... o luxo setecentista utiliza, modificando-as, as diversas 
formas através das quais antes se exprimia a linguagem da autoridade, mas que, tendo entretanto deixado de corresponder ao conteúdo que fora o seu, se transformaram em fins em si próprias: o artista pode delas servir-se de acordo com o seu capricho, para satisfazer o gosto da variedade ${ }^{43}$.

Citando Starobinski, Alessandra Ponte nos levou a pensar que no século XVIII, especialmente nas artes decorativas, os símbolos que antes eram repletos de significados não passavam mais agora de objetos de satisfação e de prazer gratuito ${ }^{44}$.

Por outro lado, seria preciso verificar o teor de classicização no âmbito da arte rococó, que absorveu tanto uma permanência de elementos do barroco depurados por um sentido de delicadeza quanto um intenso processo de recuperação do Antigo em direção ao Neoclassicismo. Havia, de fato, desde meados do século XVIII, um renovado interesse pela Antiguidade, causa e consequência de novas escavações arqueológicas e do pensamento Iluminista que justificaria, por outro caminho, a evocação do Cupido na festa de chegada do primeiro bispo à cidade de Mariana, em 1748. No entanto, nossos anjinhos do trono episcopal entalhados pelas mãos de Aleijadinho - ou de outro marceneiro bastante especializado - faziam parte de uma insistente "coleção" de outros anjos, querubins e serafins, para além do mobiliário e da marcenaria, para além da talha em madeira, em direção ao universo totalizante que envolveu das molduras de mapas à azulejaria, da decoração interna da arquitetura às esculturas monumentais em pedra, espalhados por toda a geografia da arte luso-brasileira. Certamente, esta legião de personagens alados mereceria ainda outras mais aprofundadas e específicas considerações.

Recebido em: 05/05/2014. Aprovado em: 23/06/2014.

43 STAROBINSKI, Jean. La Scoperta della Libertà 1700-1789, 1964. Apud PONTE, Alessandra. Mobiliário do século XVIII França. Lisboa: Presença, 1990. p. 8.

44 PONTE, Alessandra. O móvel francês do século XVIII. In: XVIII França. Op. cit., p. 8. Mobiliário do século 